\title{
Pitch Frames as Melodic Archetypes
}

\author{
WILLIAM THOMSON \\ University of Southern California
}

\begin{abstract}
In our history we have recognized scales of some variety as keystones to music's pitch structure. And yet, empirical studies of perception and archeological appraisals of human evolution confirm an unchanging cognitive/perceptual ground for the musical experience; they render the ragas and modes and tonoi and scales of the past to be understood only as "local" explanations for things better understood by the space/time kinetics of limited elements rather than by frozen note paradigms.

This paper concludes that an empirical study of music from a broad variety of times and cultures argues for a more elemental basis: thus coinage of the tonality frame. This conceptualization reunites harmonic nucleus with temporal span, meshing as well with ancient and exotic conceptualizations of hierarchical patterning.
\end{abstract}

Submitted 2006 February 2; accepted 2006 February 24

KEYWORDS: perception, melody, melodic, harmony, tonality, form, structure

MUSICIANS have contended with at least three explanations of pitch coherence over the past three centuries. They were forced to grapple with even more when dealing with music from outside the WestEuropean orbit.

One of the three, the 12- tone world initiated by Schoenberg, is of no concern to us here; after three-quarters of a century, it continues to lack confirmation from studies of perception as more than a compositional tool.[1] The other two conceptualizations, modality and tonality, were conceived as attempts to explain something of music's perceived pitch structure. Each carries the birthmark of its origins, the ontological canons that dominated its era. In the rhetoric of learned musicians the two theories are separated, as if mutually exclusive.

This convention demands that music of Western civilization composed between 900 and 1600 - give or take a half-century on either end-is modal. Its taxonomy is confined to the diatonic set (with the preGuidonian exception of B-flat), whose permuted orderings by finalis yield eight modes.[2] Then music created after the $17^{\text {th }}$-century deadline is routinely lumped into a different pitch-structural taxonomy: it is tonal, not modal. And then tonal conditions of that duality are sometimes further refined as either of classical tonality, functional tonality, or harmonic tonality. The modal/tonal separation boasts an imposing birthright: the revered legacy of the Rameau-Riemann-Schenker triumvirate. Each in his own way defined pitch organization as a product of major or minor scales set into certain orderings of chords.

But we must ask: "Has humanity evolved in such a way that different pitch resources have been demanded as the centuries rolled by?" [3] Must that development be thought of only as a few-to-many pitch progression, with primitive pentatonic (or fewer) leading on through modality into the Enlightenment's diatonic, and hence to the dodecaphonic of $20^{\text {th }}$ century fame?

There are "evolutionary" exceptions noted on occasion from the modal/tonal duality, even beyond obvious instances of antique resonances, like those in the music of Bruckner or Vaughn-Williams. Thus Debra Mawer tells us [4] that Milhaud and Stravinsky favored "modality over tonality," as if the presence of the one negates presence of the other. And then jazz giants Miles Davis and Bill Evans claimed to improvise in the Dorian mode, even if what they produce sounds suspiciously like simple old C major.[5]

It is musicology's good fortune that a cadre of new-generation scholars has made some progress in clearing the fields of our historicistic blind alleys. Harold Powers' numerous burrowings into matters of mode, scale, räga, et al., Delores Pesce's studies of late medieval polyphony, and the analytical studies of 
Sarah Fuller have been markers toward long overdue relief. Music historian Cristle Collins Judd has helped lead the pack toward a less confining perspective of pitch structuring in pre-Baroque music over the past decade. But, sad to say, the engrained bad habits of academe are not easily broken.

The most concise statement I know of Harmonic Tonality was made in 1940 when Ernst Krenek ruled that "A tone becomes the tonic only when the central triad is built over it."[6] Since the term tonic is here inseparable from the term central triad, Krenek's claim is tautological - which is just one of several clues that assumptions implicit to his definition are flawed. Whatever may be its ultimate credibility, the Harmonic/Classical/ Functional Tonality versions are de-facto irrelevant to music lacking chords, whether as simultaneities or implied by melodic motion.

So a second probing question is in order: "Why are different theories required to define musics which in very fundamental ways sound alike?" How really different, for instance, is the pitch structuring of a Gregorian tune in certifiable Lydian mode and a $19^{\text {th }}$ century English folk song designated as "in the key of $F$ major?" And is the bassoon opening of Stravinsky's Rite really that different from any other pitch string of 6 notes with $A$ as its nucleus? Mawer calls his music modal; theorist Allen Forte finds the Rite of Spring atonal.[7] And "That's a complication," as Lawyer Frazier told Bess.

There is yet a further compounding of this conceptual dilemma: Neither modality nor tonality is touted as definitive for non-Western music. We are directed instead to the likes of Ragas or Liu-liuh or Octoechos-the chosen option depends upon the music's culture of origin-to derive official pitch sense. One must wonder if a close shave with Ockham's Razor might not be overdue; far too many "entities" seem to muddle the conceptual stew. Can we not reach an overarching consensus? A basic theory?

Despite those inroads made by musicologists like Powers and Judd, the dominant view of current musicology about such matters is bleakly historicist, anti-empirical. It argues that structural ontologies are credible only if conceived within the time and place and explanatory trappings of a music's creation.[8] Virelais of the $12^{\text {th }}$ Century, it is argued, can't possess tonality; that term, with its descriptive overlay, was not coined until six centuries later. In other words, if contemporaries formalized no conceptualizations, then we can't assume they entertained any such perceptions. The policy is as indefensible as it is quaint. If duplicated today in medicine it would hold that persons suffering inflamed joints before 1800 were in fact victims of "leaking morbid humors," which was the diagnosis of the times - since the faulty metabolism of uric acid had not yet been discovered.

The fact is that many confirmed explanations of our world enjoy no conceptual basis in the lore of "their times"- from the cave paintings of Lascaux to heavenly constellations. Anthropologist Ellen Dissanayake obliquely trashes the no-concept/no-percept notion when she observes that

. . not having a word for something is not proof that the something does not exist. Many societies have no words for "love" or "kinship," yet these abstractions are evident to the outsider who names and then looks for them.[9]

So again we ask: "Must explanatory theories be different for different times and places because people change?"

Our current knowledge suggests the folly of such a conclusion. Empirical studies of our own cognitive-perceptual machinery point to rather basic and uniform processes that govern the way we humans obtain a sense of dynamic wholes from successions of pitches-a sense of music. And furthermore, our knowledge of peoples who preceded us and who enjoyed different cultural trappings suggests that they were not different from us in the way they experienced music. In fact, what we know today suggests that the basic properties and operations of being human have not changed in thousands of years. As archeologist Steven Mithen explains, the most recent act of humanity's evolutionary scenario began around 10,000 BC, when Homo sapiens helped usher in the Holocene era.[10]

As a species, we all arrive equipped with much the same sensory powers and predispositions that enable us to meet the external world and survive. These genetically-endowed talents stem from common needs; they are part and parcel of what psychologist Eleanor Rosch calls "Cognitive Economy."[11] They enable us ". . . to classify, to sort impressions and perceptions into some kind of order such as normal and abnormal, safe and dangerous, edible and inedible ... and so forth." [12]

Empirical studies of music perception from the past three decades don't support the kind of multilateral division imposed by musicologists and music theorists. Indeed, such a conceptualization is foreign to the burgeoning field of perceptual psychology, as a brief review of that literature's high points can reveal. 
Especially prominent are relevant studies by Schellenberg \& Trehub (1966a-b), Deutsch (1980), Krumhansl \& Keil (1982), Castellano, Bharucha, \& Krumhansl (1984), Butler, (1989), Bharucha (1996), Huovinen (2002), and Giangrande, Tuller, \& Kelso (2003). Above all, each manages to establish the persuasive powers of context on any musical event. Each confirms something that comes as bad news for many of our PostMod colleagues: we are not blank slates. We play the perception game with loaded dice. One instance is our decided predilection for $5^{\text {th }}$ and $4^{\text {th }}$ (ic5) within the kinetics of pitch patterning, relationships that play prominent roles - even determining roles - in the musical experience. Try as we might, we seem unable to escape these predispositions.

We furthermore derive structure from pitch dynamics in time rather than from itemizing the tiniest sound bits. And thus "empirical" studies that only count notes to produce structural information, without attending to parametric kinetics, are misguided. Drawing a parallel between psycholinguistics and music theory, David Butler (1989) makes a crucial point when he observes that "it is certainly clear that major revelations of deep structures in grammar did not issue from repeated and careful studies of the alphabet."'[13] And counting notes inhabits the same wasteland.

Erkki Huovinen of Finland finds indispensable the recognition of a limited set of pitch frames in describing the tonal residues of real-time pitch motion.[14] Data from his six empirical studies affirm the prominent role played by interval-class (ic) 5 , leading to his conclusion that such intervals $\left(5^{\text {ths }}\right.$ and $\left.4^{\text {ths }}\right)$ "should be seen real intervallic sign posts for listeners in their quest of sense from pitch sequences." In this, Professor Huovinen echoes a conclusion reached by Paul Hindemith more than sixty years ago. But Huovinen goes further. His study adds hard empirical support to the idea of pitches framed in time as perceived reality, data that exceeds mere informed hunches or numeric formulations.

A recent study of event-related electrical potentials of the brain $(E R P)$ by Granot and Donchin [15] supports several common-sense notions of our responses to pitch patterns: (1) a string of pitches (sets of seven in their study) constrains or does not constrain our expectations of a succeeding pitch. How so? It depends on the intervallic ordering of the particular series [16]; (2) a broad difference separates the way we listen to passages of clear pitch orientation and those of ambiguous orientation; and (3) the musically trained are not alone in their sensitivity to fundamental tonal/harmonic propensities.

Nor are constraining auditory traits limited to our West-European populace. Patterns of straightforward pitch hierarchy (i.e., of $0,4,5$ interval class content) are encoded and remembered by listeners outside our cultural milieu with comparative ease. A study by Castellano, et al. (1984) concludes that native listeners to the music of North India respond with the same hierarchical biases exhibited by listeners from West-European cultures. A similar study by Nam (1998) finds a conventional tonal hierarchy-with ic5 (perfect $4^{\text {th }}$ or $5^{\text {th }}$ ) paramount in the p'iri repertory of traditional Korean court music. Within that music he notes "analogous tonal hierarchies," these dominated by "'finalis' tones consistent with the 'tonic'."[17]

Such experiential propensities are not limited to highly-conditioned adults. Studies of six-year old children by Schellenberg and Trehub (1996), by Trainor (1997), and by Zentner and Kagan (1996) make manifest that $8^{\text {ves }}, 5^{\text {ths }}$, and $4^{\text {ths }}$ provide stable referential bases within strings of successive and simultaneous pitches. Studies by Trehub, Endman, and Thorpe (1990), Lecannuet (1995, 1996), and by Fassbender (1996) confirm timbre discrimination as a fact of life 3 to 4 months before birth. A classic 1982 study by Krumhansl and Keil concluded that the pitch hierarchy, with ic4 and ic5 as central elements, has been internalized by $8-9$ years.

Data of a more generalized nature, from studies of melodic contour by Dyson and Watkins (1984), and Jones (1987), isolate the power of contoural and contextual factors (highest/lowest, first/last) for imbedding a pattern into a young listener's memory. Psychologist Lyle Davidson has found three constituents endemic to children's music-making, one of which he calls the "tonal frame. "It's a component that designates the pitch interval outlining the temporal play of an improvised melody."[18]

These conclusions help to ratify the perspectives voiced by archeologist Steven Mithen and confirmed by anthropologist Ellen Dissanayake: the human aural experience is no haphazard production line, one whose finished product changes with the fashion of the times. We don't process sound information as separate bits nor according to style-conditioned fashions of the times. As psychologist Deutsch explains, “...we form sequential groupings out of combinations of elements."[19] In other words, we build things as we go. And we "build" them in ways that do not vary, culture-to-culture, century-to-century. In the words of psychologist Ernst Terhardt (1989, p. 197), "there exist a number of universal auditory phenomena that govern--or at least affect--the perception of any type of music." 
If it is true that the basic human perceptual predispositions and capabilities have remained unchanged, culture to culture, century to century, then it seems questionable that exclusive structural theories are required. And if the artifacts of diverse cultures, both ancient and modern, share common traits with our own, we are overdue an encompassing theory of description and explanation. And thus the formulation of what I call the Tonality Frame.

In hearing a melody, the ensuing relationships-the hierarchical bunchings of the pitch string - represents the transformation of separate bits into their unique contextual roles.[20] The tonality frame is just one such covering formulation. It suggests some rather elemental things about the creation music and perception of music. It is a broadly applicable archetype of pitch organization, [21] one that draws us closer to our heritage than the fractured musicology of our times. For one thing, the framing action recognizes the space/time kinetics endemic to the musical experience. It thereby avoids the fundamental error in tonal hierarchy theories of the past exposed by Butler, products of "a rigid, time independent conception."[22]

It gives yet another helpful budge toward ontological reality: it thrusts our notion of harmony back to where it belongs, as an elemental participant basic to the spatial property of music's time/space projection. With some sense of irony, it returns us to the Aristoxenian sense of twenty-three centuries ago, when ". . . the name of Harmonic is to be regarded as one of the several divisions or special sciences embraced by the general science that concerns itself with Melody."[23] The tonality frame also helps breech the gap between us and exotic musics of past ages, meshing with remarks such as those made by Chinese Prince Chu in a treatise of 1535. They tell us of the "harmonic relationship" in ancient Chinese melody that bears between initial and final pitch. [24] We can witness just such "harmonic relationship" in music through time from over the world.

\section{FRAMES: CAUSE AND CONTENT}

The melodic interactions of "London Bridge," shown in Figure 1, establish some pitches as more basic than others. [25] As in hundreds of other children songs, they fence off a pitch envelope. In this case it is one of a $5^{\text {th }} f>\mathrm{c},(7-0)$. [26]

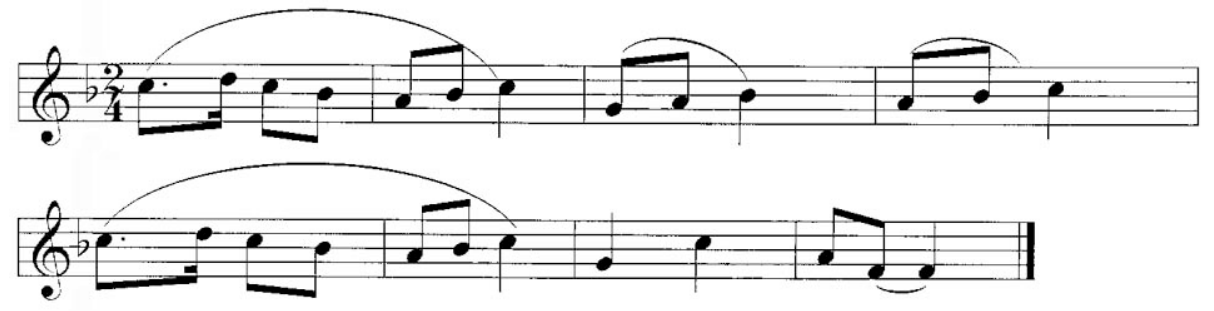

Tonality Frame:

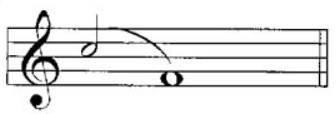

Fig. 1. "London Bridge" (children’s song).

The eminence here of pitch $c$ is obvious. It initiates motion - and on a downbeat. It persists, providing the return point for ensuing motions both above and below. It is the operational lid for the whole melody. On the other hand, pitch $f$ is the final sound as well as the tune's operational bottom. In context, it enacts rhythmic, contoural, and formal closure. Invested by these linked actions, the $c-f$ pair assumes a global function; it is the essence of the melody's pitch coherence. Every time I rehear the first seven pitches in this order and timing, that residue frame ensues (with a high degree of probability). It is my de facto context, that "contextually prescribed course" so aptly described by philosopher Andrew Ushenko.[27]

But location isn't everything, and our pitch pair is not an egalitarian mating. Another property is paramount here as well: vectorial focus plays a major role in the cognitive residue that is the tune London Bridge. The whole melody's kinetics "point to" $f$ as a focal pitch, its tonic, its root.[28] Given the $C-F$ relationship, the latter pitch is that interval's harmonic nucleus, its root. The general condition is too familiar from life to demand much comment: a content of hierarchy entails a locus of power, a rallying point. In the pitch world of music that rallying point lies in the bottom-heavy tonal shape known to $u$ all 
since our prenatal auditions: the Harmonic Series.[29] That vaunted archetype does not give us absolutes; it yields a condition more on the order of what philosopher John Searle calls a tropism, a "tending toward." [30] We don't necessarily audiate "tonic $F$ " every time we think the pitches $C$ and $F$, whether as a succession or as a simultaneity.

It is in this sense that $f$ enacts harmonic closure in real time for London Bridge. It is, to borrow a metaphor from vision, the melody's perceptual "vanishing point."

The next three melodies (Figures 2, 3, and 4) are from quite different cultures and times, but like London Bridge, each projects a $5^{\text {th }}(0-7)$ as its pitch envelope.

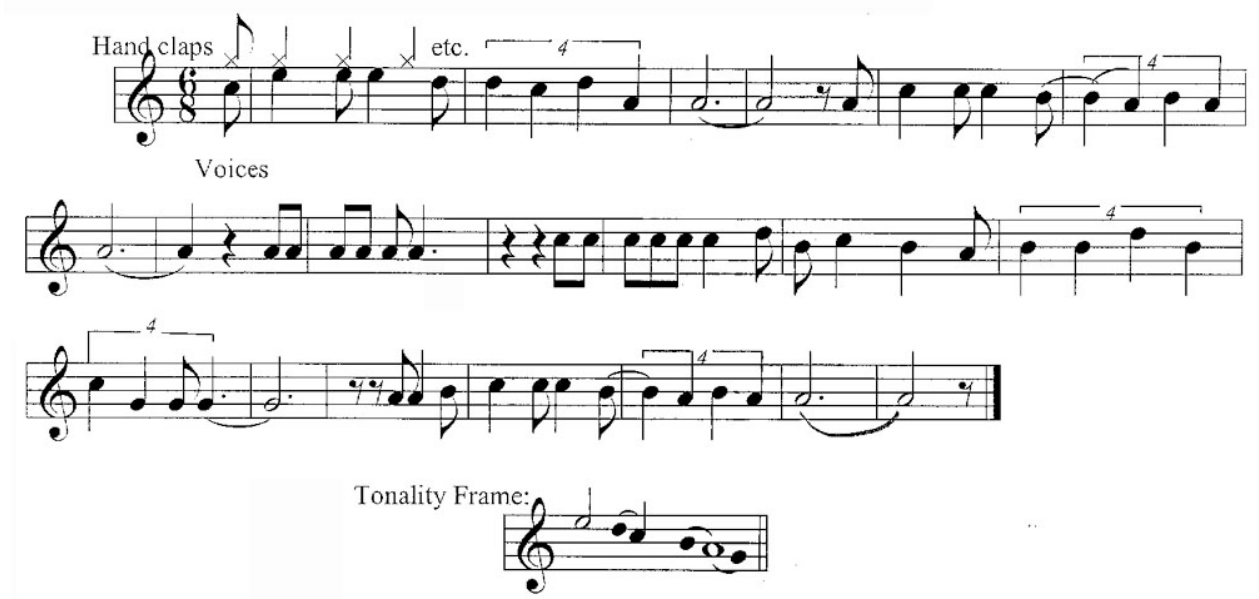

Fig. 2. African Song (Coll J.H. Kwabena Nketia. African Music of Ghana, 71-72), pitch synopsis.
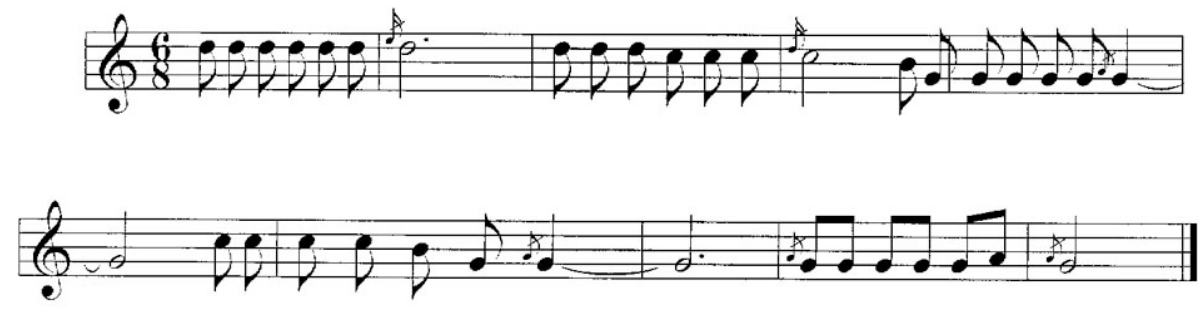

Tonality Frame:

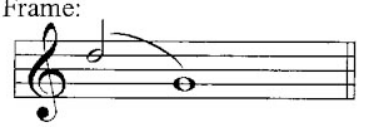

Fig. 3. Ojibway Song (American Indian) Coll. Hoffman, Oxford history of Music, \#30, p. 64, pitch synopsis.

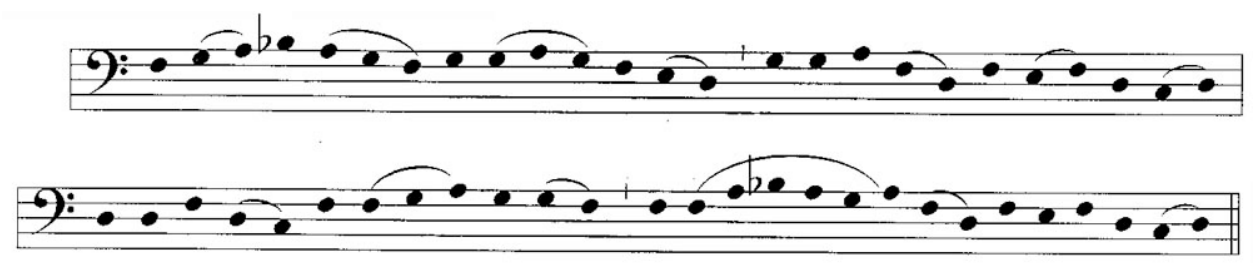

Tonality Frame:

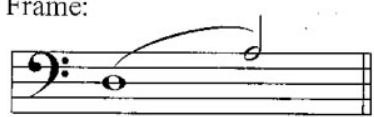

Fig. 4. Gregorian Hymn (Liber Usualis, 575), pitch synopsis. 
All three frames arise from the same kinds of pitch kinetics, hierarchies yielded by some mixture of the following: [31]

(1) formal prominence (unit endings or beginnings);

(2) rhythmic prominence (metric or loudness accentuation);

(3) frequency of occurrence (including durational dominance, repetition);

(4) contoural locus—-highest, lowest, and/or pivotal—within defining patterns;

(5) prominence of a simple harmonic relationship $\left(8^{\mathrm{ve}}, 5^{\text {th }}, 4^{\text {th }}\right)$.

A slightly different frame, albeit product of the same causes, is embedded in Figures 5 and 6 . But here the areas of containment extend to a tonic-tonic' octave $\left(0-0^{\prime}\right)$.

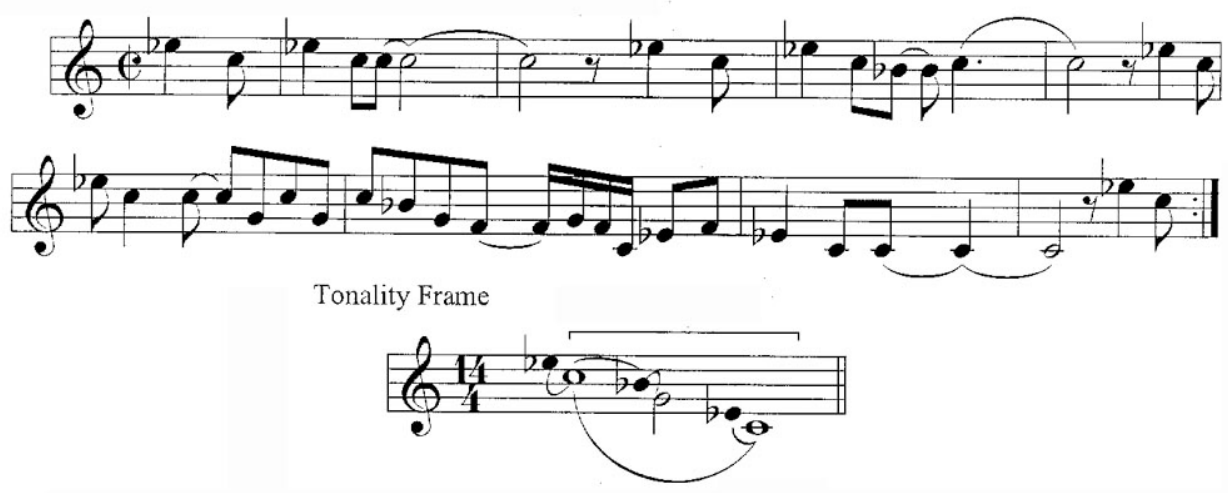

Fig. 5. Now Your Man Done Gone, early $20^{\text {th }}$-Century Alabama Folk Song (Coll. Harold Courlander, Negro Folks Music USA, 108).

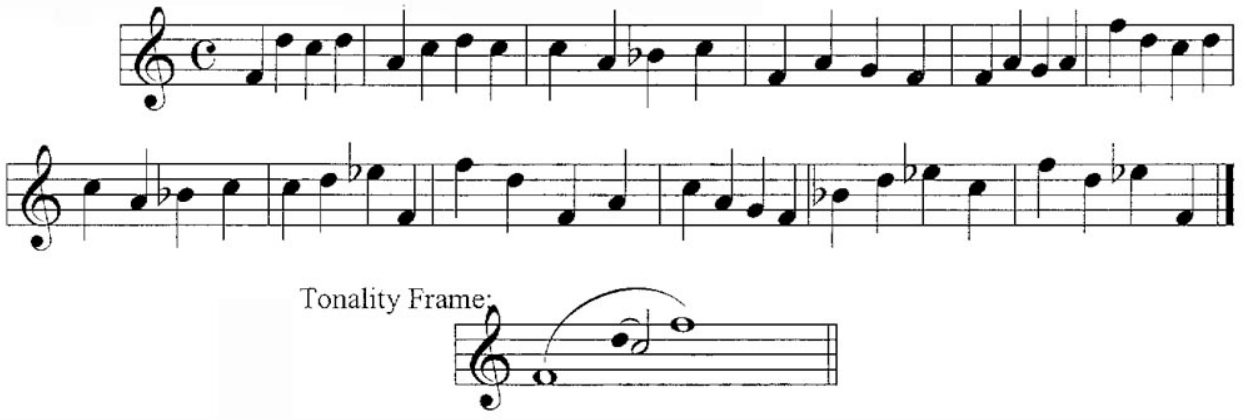

Fig. 6. Here We Are Gathering Duckweed, Tang Dynasty, 618-907 A.D. (Coll. Laurence Picken. In Studia Belae Bartók Sacra, 164).[32]

And then the next three melodies (Figures 7, 8, and 9) project octave frames but of yet a different caste: their tonics lie within rather than as outer boundaries, frames of (7-0-7') rather than (0-7-0'). 


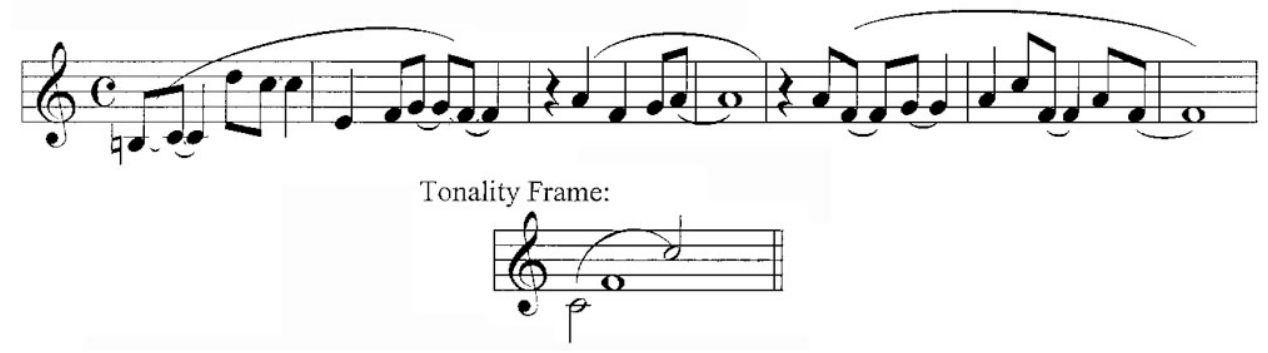

Fig. 7. Duke Ellington, I Got It Bad and That Ain't Good, pitch synopsis.
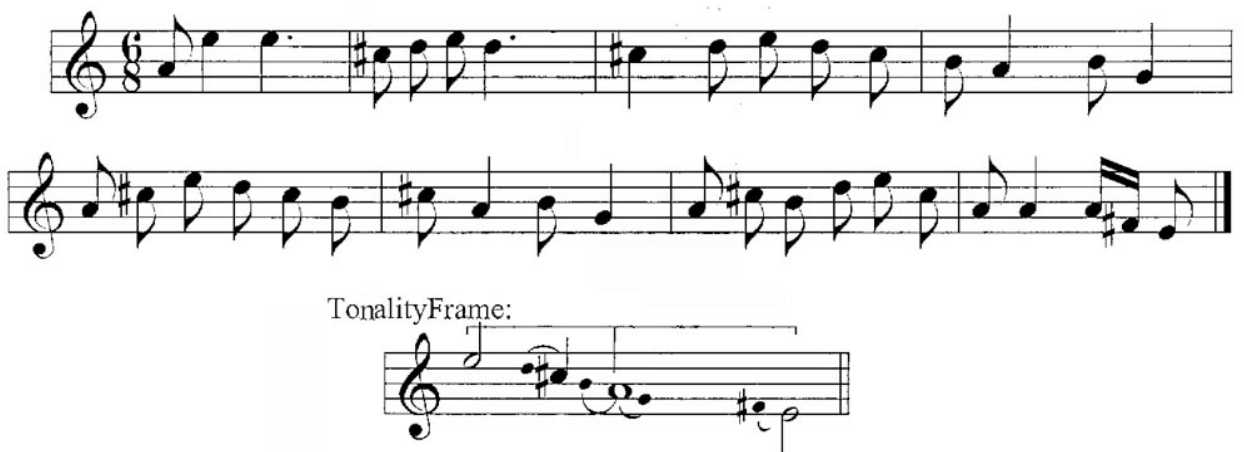

Fig. 8. Hymn to Seikilos, epitaph, Greek burial marker, c. 100 BC (Davison \& Apel), pitch synopsis.
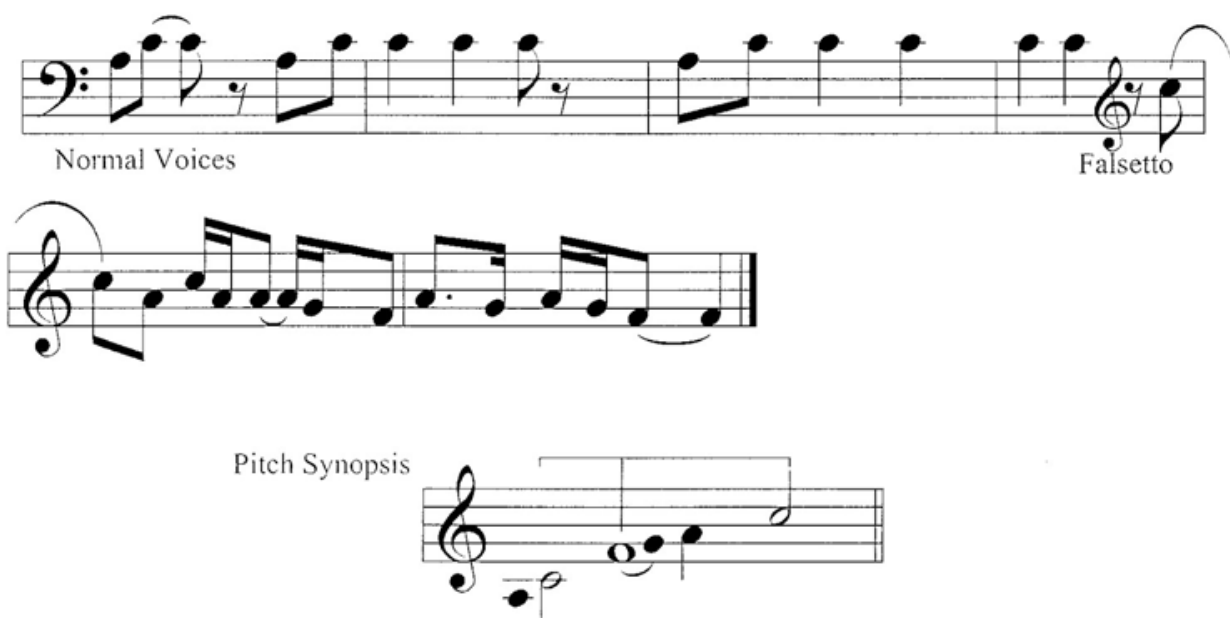

Fig. 9. Navajo Antiphonal Song (Coll. Laura Boulton, Navajo Songs, trans. W. Thomson), pitch synopsis.

Less-sophisticated melodies, more restricted in range yet beyond the realm of chant, often span a $4^{\text {th }}$, projecting the upper pitch as tonic, as in Figure 10. 


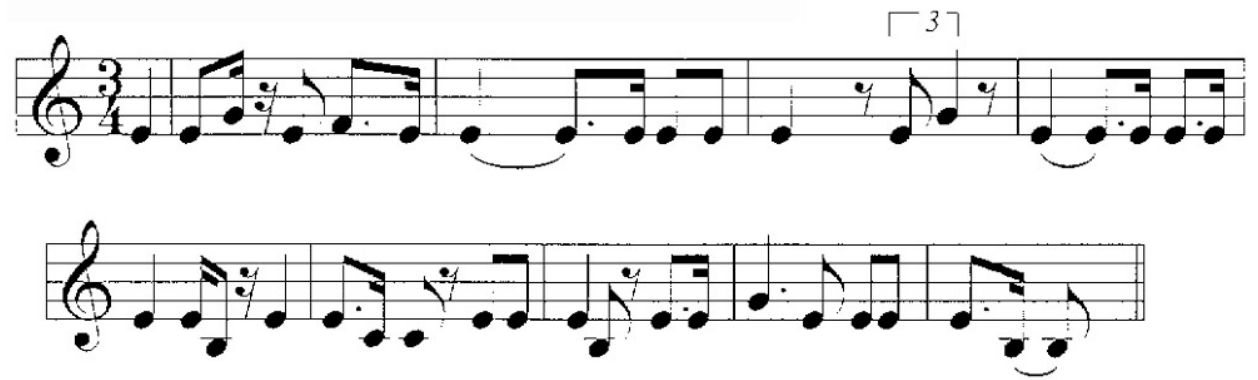

Pitch Synopsis

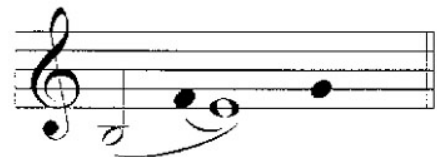

Fig. 10. Burmese Prayer Song (Coll. Marius Schneider, \#57 in The New Oxford History of Music, I, p. 67), pitch synopsis.

The preceding examples do not represent rarities from their respective cultures. They are typical. I have nonetheless encountered many primitive tunes that display no such assured framing. More chant-like, they usually are dominated by simple return patterns around coequal contenders, as in Figure 11.

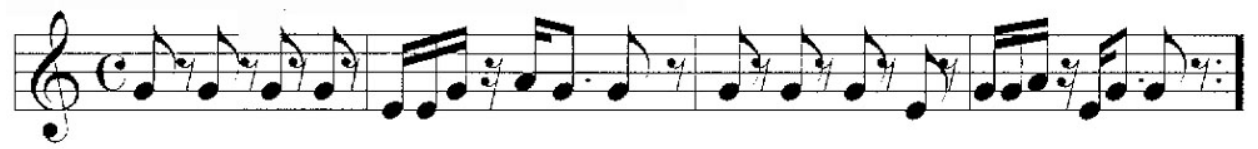

Fig. 11. Vedic Melody (Coll. E. Felber. \#30, Die indische Musik der veidschen und der Klassischen Zeit), pitch synopsis.

Perhaps composers and listeners for such tunes had acculturated inclinations for assigning referential functions, reasons undocumented and beyond our ken today. Or maybe tonal orientation simply was not an issue in that music's perceptual milieu. Or finally, let us not assume that structural ambiguity would not at times play a role in the music of another culture, as it does in ours.

There is a further potential model of the frame. Like Figure 11, some tunes project pc 4 as a framing member. Most I have found are from West-European sources, especially in folk or pop songs of the $19^{\mathrm{th}}$ and $20^{\text {th }}$ centuries, but the species turns up in art music as well.[33] Characteristically, they are melodies conceived - and usually performed - with some kind of chordal accompaniment. Note in The Yellow Rose of Texas (Figure 12) that pc 7 plays a strong role as well.

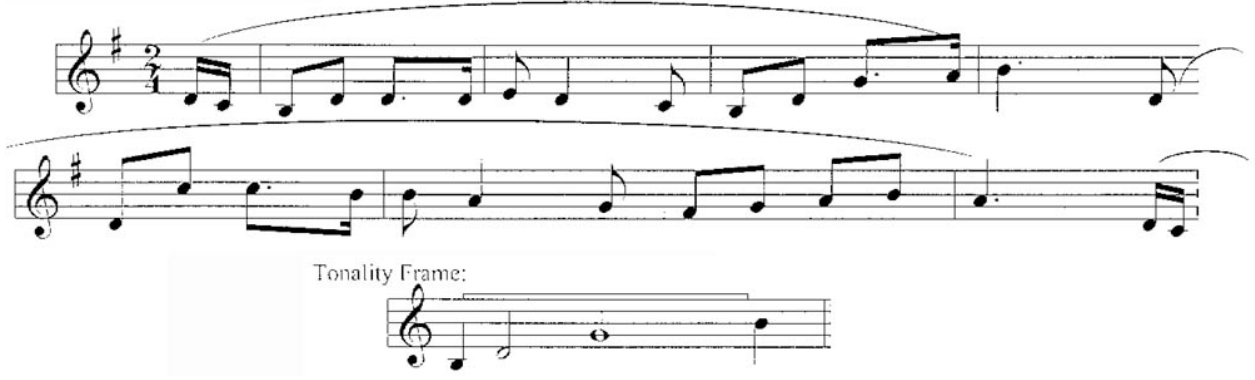

Fig. 12. The Yellow Rose of Texas (Civil War folk song of the Confederacy), pitch synopsis.

And then there are wide-ranging melodies as in Figure 13, whose total frame exceeds an octave yet retains a compound $8^{\mathrm{ve}}, 5^{\text {th }}, 4^{\text {th }}$, or $\mathrm{M} 3^{\text {rd }}$ as tonal enclosure. 


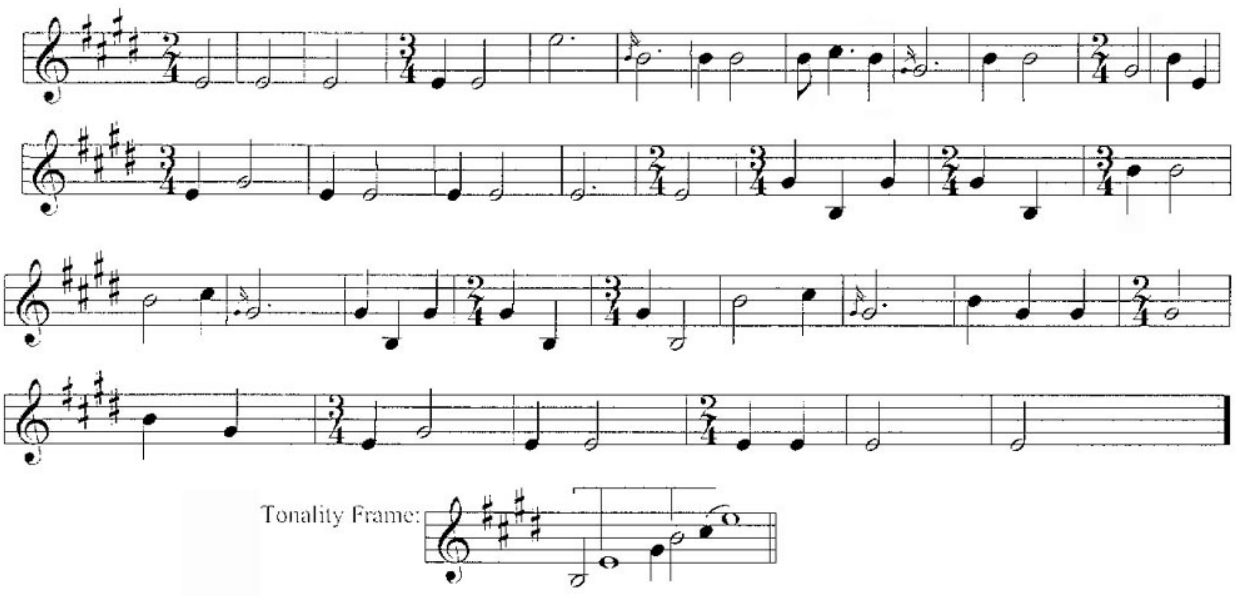

Fig. 13. Dischi Biyan, Navajo Mountain Song (Coll. Natalie Curtis. The Indians'Book), pitch synopsis.

Although I have purposely sought them out, rare is the melody in which the minor $3^{\text {rd }}$ (pc 3 ) acts as an unassailable framing member. When that relationship seems incumbent as a line's lower boundary, it proves to be a passing flirtation within an encompassing frame that temporarily projects the relative minor key (see Figure 14). Or in other instances the melody's final pitch robustly supplants all preceding kinetics.[34] The interior dynamics of the song Dyak strongly suggest a minor $3^{\text {rd }}(0-3)$ framing of $D-F$. But pitted against the first and final $F$ and the prominence of $C$ in the mid-section, a residual $D-F$ union, as formative image, dims decisively.

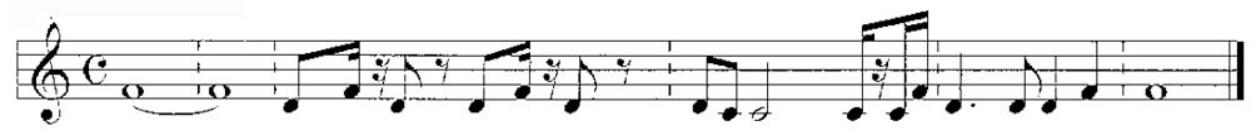

Fig 14. Dyak, folksong of Borneo (Coll. Marius Schneider. \#86 in The New Oxford History of Music, I, p. 70), pitch synopsis.

Even more frequent is the minor $3^{\text {rd }}$ (pc 3 ) hinted as a frame's upper boundary. But these invariably turn out to be decorative shadings of tonic, as in the "blues $3^{\text {rds }}$ of Now My Man Done Gone (Figure 5), thus failing to achieve a structural role. Although melodically prominent, pc 3 is auxiliary in function.

Folk tunes sometimes vacillate provocatively between the $5^{\text {th }}$ of a major scale and the $5^{\text {th }}$ of its relative minor, as in Figure 15. Here the $e$ prevails in the end. A gentle shifting from one frame to another-modulation in its simplest form - nonetheless occurs within the melody's interior. It suggests a degree of sophistication we tend to think missing in the music of less developed cultures.

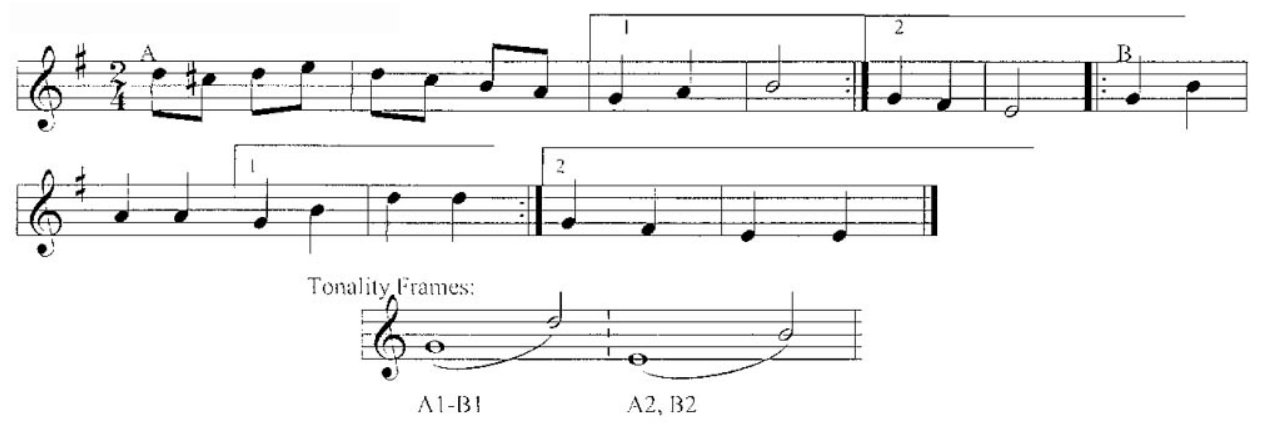

Fig. 15: Halo nelo, Bulgarian folkdance (Coll. Kacarova Kukudova. Studia Bela Bartók Memorae Sacra: 81), pitch synopsis. 


\section{MUSIC OF TEXTURE}

Tonality frames usually operate in richly polyphonic textures of "common practice" music in the same way and using the same building blocks found in simple unadorned melody. As mentioned earlier, the pitch simultaneities of chords add an immediate and significant shaping dimension; sometimes they confirm, sometimes they are at odds with melodic shapings.[35] Melody often is wholly dependent upon chords for tonal orientation, as in tunes like Hoagy Carmichael's Stardust or Duke Ellington's Sophisticated Lady. But radically simple and direct examples of melodic/chordal complementation aren't rare (e.g., George Gershwin's Someone to Watch Over Me, Richard Rodger's Blue Moon).

I have been surprised at how frequently pristine framing actions, all laid out with a common tonic, shape the individual lines of a multi-voice texture. Note the bracketed frames of Figure 16, each projecting fealty to pc $G$, and its prominent $5^{\text {th }} D$. And let us recall that by historians' ruling this music is modal, not tonal.[36]
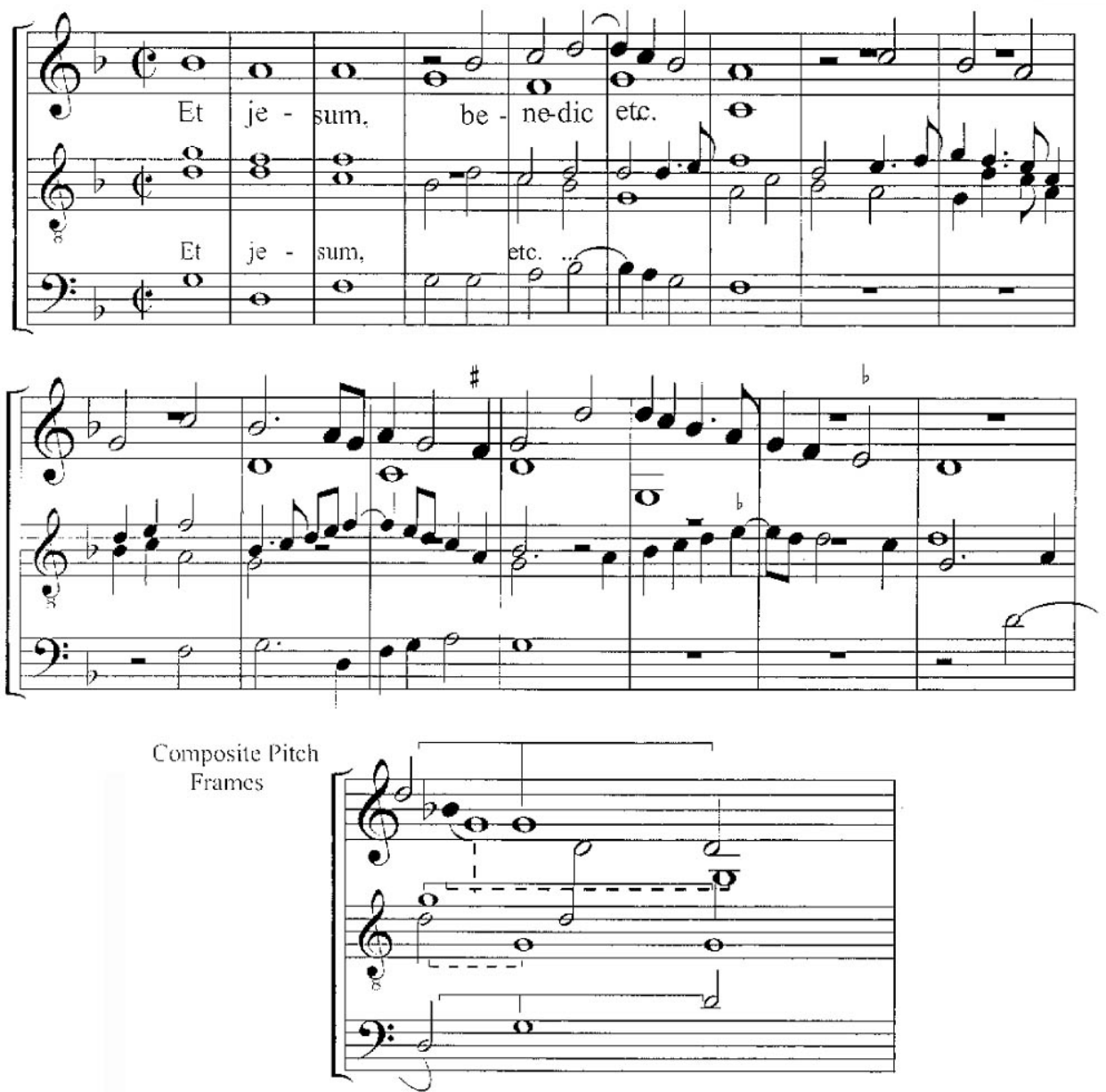

Fig. 16. Josquin Des Prez, Salve Regina, mm 1-16, pitch frames.

I hasten to add that some polyphonic textures from the West-European repertory do not so emphatically reflect the obvious defining tessituras found in most Renaissance polyphony. And yet, music from the Bach-through-20th Century often does, bearing outer voices that routinely cut a coordinating frame, ensuring the pitch bunching over time that is tonal unity.[37] Note the top-to-bottom framing of Figure 17. This is a part of the endearing directness and simplicity of music from the Haydn-Mozart era. 

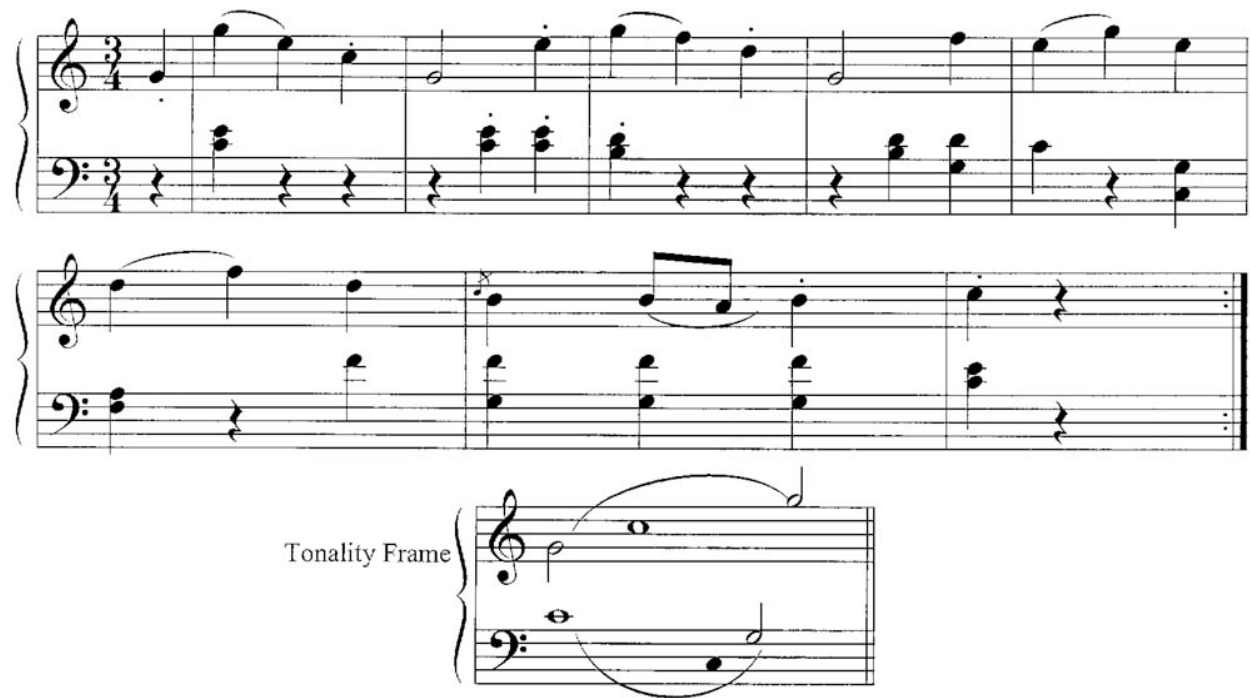

Fig 17. W. A. Mozart, opening bars, Minuetto (c. 1783).

As in monophony, compound textures sometimes exhibit the kind of successive major/minor duality found in melodies like Figure 18. The two voices of La Mintso project this duality, the lower decidedly framed by the $a-e 5^{\text {th }}$, the upper contained within the duality of an $e-g / a-c^{\prime} 6^{\text {th }}$.
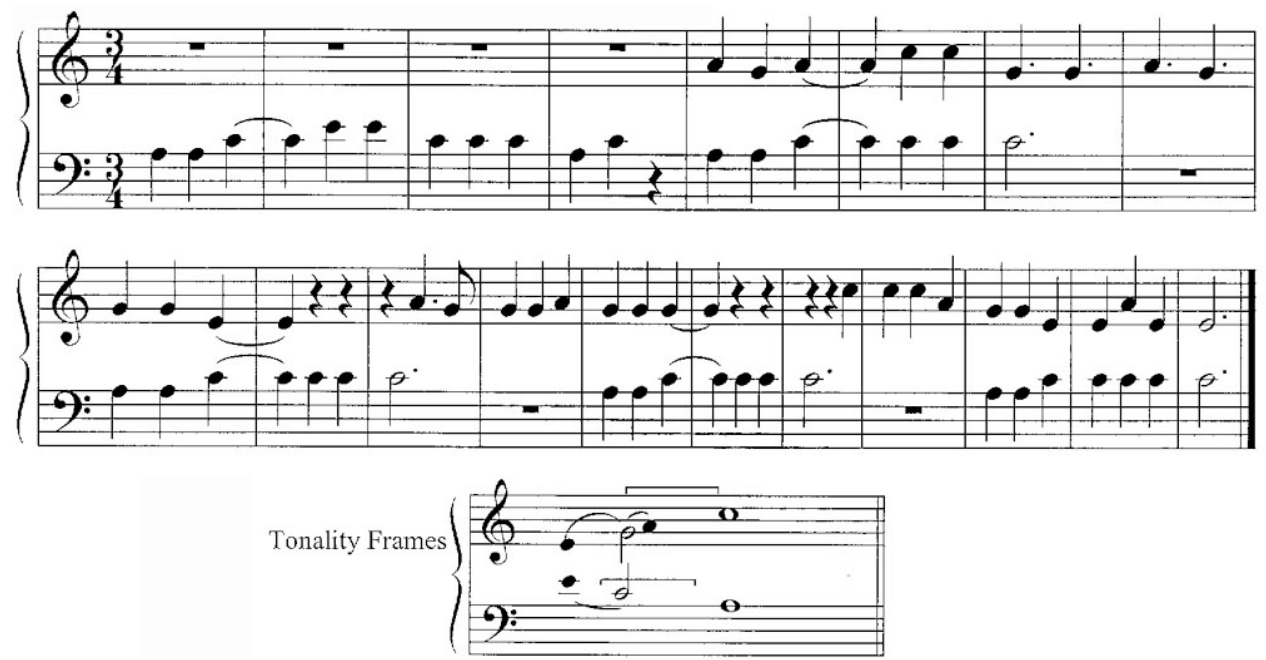

Fig. 18. La Mintso, Folksong of Ghana (Coll. J.H. Kwabena Nkhetia. African Music of Ghana: 127-28), pitch synopsis.

\section{CONCLUDING DISCUSSION}

Let us note that several fascinating inferences can be drawn about the tonality frame as structural paradigm. The theory itself derives from and is rooted in empirical data. It provides a post-facto insight into certain aspects of ancient conceptualizing, reminding us of our forebears' sagacity. The abundance in world melodies of pitch frames $\left(0-7-0^{\prime}\right)$ and $\left(7-0-7^{\prime}\right)$ for instance, testifies to the elemental rightness of the Authentic and Plagal distinction in modal taxonomies. That archetypal division was conceived as a product of an astute observation: melodic tessitura is a matter of vital structural consequence. Two orderings were seen to prevail: final-final $\left(0-0^{\prime}\right)$, dominant-dominant $\left(7-0-7^{\prime}\right)$.

The same condition is further reflected in classical Indian theory by the specialized roles of scale degrees such as a "central tone;" [38] only the $8 \mathrm{ve}, 5^{\text {th }}$, and $4^{\text {th }}$ act as Samvâdi, or consonances. As Donald Lentz makes clear, [39] that heritage recognized a fundamental duality, wherein scales begin either on $S a \bar{o}$ or 
$M \bar{a}$, yet they are fleshed out within different registral plots from the same pitch collection. Most cogent to the tonality frame is scholar Richard Weddess's description of the äläpa, or "warmup" opening section of the classical räga performance. Going back many centuries, the tradition found it developed

within an octave span, optionally extended above and/or below; starting from the Predominant - equivalent to the modern tonic $S \ddot{a}$-located at the top, the bottom, or in the middle of this octave span, the melody expands in a top-down, bottom-up, or middleout direction.[40]

And finally, even pre-Christian Greek theory adroitly echoes the same elemental insight. The classic model (the Tonoi) consists of two disjunct tetrachords, the ( $\left.{ }^{\prime}-0-7\right)$ frame - or, if you will, a hypo-mode form as in Figure 19. And thus the Greek mode Aristoxenus and Ptolemy called Phrygian [41] inhabits the Hymn to Seikilos of Figure 8, its A4 operating as "dynamic" Mese within the (7'-0_7) frame.[42] Most importantly, it here resonates with pseudo-Aristotle's claim [43] that

In all good music mese occurs frequently, and all good composers have frequent recourse to mese ... mese is as it were a conjunction among sounds and more so than the other notes, because its sound occurs more often.[44]

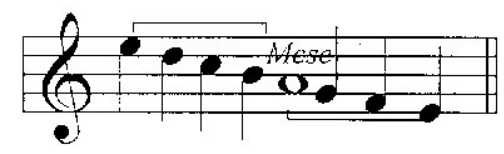

Fig. 19. Greek Phrygian octave species.

These early structural taxonomies were empirically derived-in the truest sense of that term. They were not narrowly conceived; they recognized the complex time/space dynamics that music projects. In some details they were more incisive than the styles-driven prescriptive theories of recent history, their explanations more accurate, less encumbered by ideological precepts. It is one world, after all.

\section{NOTES}

[1] Except for a tentative suggestion in the Krumhansl, Sandell, and Sargent study (1987), empirical evidence that a 12-tone row per se can project any form of pitch cohesion has not emerged. See Deutsch (1980), Francès (1954), Thomson (1999, 231-241).

[2] There have been convincing contradictions of this view over the years. Musicologist Curt Sachs argued a reasonable - and largely ignored_-perspective in 1943 ("The Road to Major").

[3] This was the perspective favored by Schoenberg and others early in the $20^{\text {th }}$ century.

[4] In Darius Milhaud: Modality \& Structure in Music of the 1920s, 2).

[5] See my discussion of this taxonomic/perceptual dichotomy in "On Miles and the Modes."

[6] In Music Here and Now, 108.

[7] Forte, The Structure of Atonal Music, ix.

[8] Thomas Christensen (1993) sounds the conventional warning that we can't trust judgments unsupported by coeval accounts. We risk, he tells us, "projecting our own culturally based conceptions . . upon a repertoire for which it has no conceptual basis." See the discussion of "The No-Concept/No Percept Fallacy" in Thomson (1999), 62-84. 
[9] What is Art For, 35.

[10] The Prehistory of the Mind, 23. Several recent archeological discoveries suggest that his dating may be a bit conservative.

[11] In "Principles of Categorization," 28.

[12] Dessanayake. Wolfgang Kohler explained the process long ago (Gestalt Psychology, 32) as the segregation of "circumscribed wholes that makes it possible for the sensory world to appear as utterly imbued with meaning..."

[13] "Describing the Tonality in Music," 234.

[14] Pitch Class Constellations, 2002. Huovinen adopts my term tonality frame in naming these.

[15] Granot \& Donchin (2002), "Do Re Mi Fa Sol La Ti-Constraints ....”

[16] As we can imagine, constraint comes readily with an opening that outlines a potential tonic chord, a pc series such as $0-0$ ' 7-4 (or $1-1$ ' $-5-3$ in diatonic lingo).

[17] Nam, 247.

[18] In “Tonal Structure of Children’s Early Songs,” 363.

[19] Deutsch, 1982, 201.

[20] Philosopher Andrew Ushenko touched on this transforming process many years ago (Dynamics of Art, 38). He noted that the power exercised by sensory data ". . . takes the form of a felt pressure or tension that forces the beholder's perception and imagination into a contextually prescribed course." It is a property John Searle later designates a "tropism" (see Infra p. 10).

[21] That is, for music in which some sense of pitch coherence, or tonality, prevails.

[22] Loc. cit., 223.

[23] Macran, The Harmonics of Aristoxenus, 165.

[24] Levis, Foundations of Chinese Art Music, 120.

[25] I am not yet talking about what Fred Lerdahl (Tonal Pitch Space, 193ff) calls "Finding the Tonic." Tonics constitute a higher order condition than "pitches of melodic primacy." It's the latter we seek now.

[26] I designate pitches herein by those of the chromatic octave, $012345678910110^{\prime}$. Thus the tonic pitch is 0 , its fifth 7, its octave above, $0^{\prime}$, and so on.

[27] See note \#20 above.

[28] Without considering internal kinetics, an ending pitch, as terminal event, holds an edge over another pitch of early dominance, including initiating pitch. Thus the prominence of finalis - sometimes excessively so-in the chant taxonomies of history.

[29] Psychologists Marcel Zentner and Jerome Kagan conclude that “...the human infant may possess a biological preference that makes consonance perceptually more attractive than dissonance." The interuterine child's ability to distinguish voice timbres are thoroughly established, and this talent demands apprehension of the series. The human fetus responds to environmental sounds by the sixth month 
according to Werner and Marean in Human Auditory Development. Also see Lecannet, Granier-Deferre, and Bushnel "Human Fetal Auditory Development," as well as Dissanayake, 2000.

[30] The Rediscovery of Mind, 173.

[31] These can be made more complicated, but I prefer keeping them simple. Relevant studies date from as early as Bingham (1909), through Ortmann (1926), to Huron and Royal (1996), through fastidious studies such as Lerdahl's (2001).

[32] I'm skeptical of this melody's rhythmic notation, but the pitch ordering is securely documented from its alphabetic notation.

[33] Brahms had a soft spot for the pc 4 mediant, a good example being the opening theme of his Ballade in $D$, Op. 10 No. 2, but the relative infrequency of pc 4 as a framing ingredient is a continuing enigma. Thus far I have found radically fewer examples than those with pes 0 or 7 as boundaries.

[34] Which is not to say that a final pitch supersedes all other considerations. It sometimes bows out to the bunching ordained by preceding events.

[35] Early "polytonal" composers created colorful harmonic palettes by joining a simple chordal pedal with a melody of non-conforming tonality frame. Milhaud's Protée (Suite Symphonique No. 2) of 1920 begins with a triadic D-major base for a melody whose dominating $G$-sharps and $B$ s project a fetchingly "foreign" trajectory that hints of A-major.

[36] Cristle Collins Judd has nonetheless exploded the oversimplistic modal myth in her discussions of tonal affinities in Renaissance music - the " $U t, R e, M i$ Tonalities," as she terms them. See her "Tonal Coherence in Sacred Vocal Polyphony From About 1500.”

[37] Schenker's Urlinie/Bassbrechung as Ursatz sagely recognizes the same kind of coordinating presence, although to a degree that I find empirically untenable, even for the common-practice repertoire he examines.

[38] See Rowell, Music and Musical Thought in Ancient India, 177. And as Habib Hassan Touma observes (Music of the Arabs, 18 and 40), most Arabic modes are named for a most important tone among its pitch collection.

[39] Tones and Intervals of Hindu Classical Music, 81.

[40] The Rägas of Early Indian Music, 371.

[41] And sometimes Iastian.

[42] My 'tonic' attributions to Greek tunes are nor universally applauded. For instance, Winnington-Ingram argues (p. 4) that there is no term in Greek theory corresponding "...to e.g. the modern 'tonic' or represents a hierarchy of importance among the notes of the scale." (He may not have read pseudo-Aristotle's Problems.) Even Mathiesen (Apollo's Lyre, 465) claims $b$ ' as the tune's dynamic mese (which if true means that the term mese bears no hierarchical relevance to perceived music). He later shows $a$ ' to be thetic mese of the $e$ '- $e$ Phrygian tonus in Ptolemy's scheme of things (Figure 71, page 465), and his discussion of the Seikilos hymn (p. 150) notes that $e^{\prime}, a^{\prime}$ ' and $e^{\prime \prime}$ operate as "strong polar points." These apparent conceptual and terminological identity crises may be why Curt Sachs observed (Rise of Music in the Ancient World, 246) that so many Greek theorists were "indifferent" to mode. My conclusion: thetic and dynamic, applied to the Mese, don't enjoy the lexical precision we covet for such critical terms.

[43] Problem 19, Vol. I. Also see note \#35 above. 
[44] There are as many articulations (8) of $c$-sharp in the Seikilos Hymn. But in terms of durations, $A$ dominates with a 10.5 (eighth notes) to the 10 of $E$ and the 9 of $C$-sharp. Pseudo-Aristotle was generalizing in the right direction, of course!

\section{REFERENCES}

Aiello, R. \& Sloboda, J. (1994). Musical Perceptions. New York: Oxford University Press.

Apel, W. \& Davison, A. (1949). Historical Anthology of Music. Cambridge: Harvard University Press.

Aristotle (Pseudo-) (1924). Problems, Vol. I. Trans. by W.S. Hett. Cambridge: Cambridge University Press.

Aristoxenus (1902). The Harmonics of Aristoxenus. Ed. and trans. H.S. Macran. Oxford University Press.

Bharucha, J. (1996). Melodic anchoring. Music Perception 13, 383-400.

Bingham, W. Van Dyke (1910). Studies in melody. Psychological Review Monograph 36, 1-88.

Boulton, L. (1933/92). Navajo Songs. Smithsonian Folkways Recording \#40403.

Butler, D. (1989). Describing the perception of tonality in music: A critique of the tonal hierarchy theory and a proposal for a theory of intervallic rivalry." Music Perception 6, 219-242.

Castellano, M., Bharucha, J., \& Krumhansl, C. (1984). Tonal hierarchies in the music of North India.. Journal of Experimental Psychology: General 113: 394-412.

Christensen, T. (1993). Review of Carl Dahlhaus's Studies in the Origin of Harmonic Tonality and Joel Lester's Between Mode and Key. Society of Music Theory Spectrum 15: 94-111.

Courlander, H. (1963). Negro Folk Music, U.S.A. New York: Columbia University Press.

Curtis, N.(1905/1987). The Indian's Book. Portland, OR: Portland House.

Davidson, L. (1994). Songsinging by young and old: A developmental approach to music. In: R. Aiello and J. Sloboda, Musical Perceptions. New York: Oxford University Press, pp. 101-130.

Deliège, I., and Sloboda, J., Eds. (1996). Musical Beginnings: Origins and Development of Musical Competence. New York: Oxford University Press.

Deutsch, D. (1980). The processing of structured and unstructured tone sequences. Perception \& Psychophysics 28: 381-389.

Deutsch, D. (Ed.) (1982). The Psychology of Music. San Diego: Academic Press.

Dissanayake, E. (1988). What is Art For? Seattle: University of Washington Press.

Dissanayake, E. (2000). Antecedents of the temporal arts in early mother-infant interaction. In: Wallin, N.L., B. Merker, \& S. Brown (Eds.), The Origins of Music. Cambridge, MA: MIT Press, pp. 388-410

Dyson, M.C., and Watkins, A.J. (1984). A figural approach to the role of melodic contour in melody recognition. Perception \& Psychophysics 35, 477-488. 
Fassbender, C. (1996). Infants' auditory sensitivity towards acoustic parameters of speech and music. In: Deliège, I., and Sloboda, J., Eds. Musical Beginnings: Origins and Development of Musical Competence. New York: Oxford University Press, pp. 56-87.

Felber, E. (1912). "Die indische Musik der veidschen und der Klassicschen Zeit," in Sitzungsberichte der Alad, der Wissenschaft. Vienna.

Forte, A. (1973). The Structure of Atonal Music. New Haven: Yale University Press.

Francès, R. (1954). Recherches experimentales sur le perception des structures musicales. Journal de Psychologie 45: 78-96.

Francès, R.(1958). The Perception of Music (trans W. Jay Dowling, 1988). Hillsdale, N.J.: Erlbaum Associates.

Fuller, S. (1998). Exploring tonal structures in French polyphony of the fourteenth century. Judd, C. C., (Ed.). Tonal Structures in Early Music. New York: Garland, 61-86.

Giangrande, J., Tuller, B., \& Kelso, J.A.S. (2003). Perceptual dynamics of circular pitch. Music Perception 20, 241-262.

Granot, R., \& Donchin, E. (2002). Do Re Mi Fa Sol La Ti-constraints, congruity, and musical training: An event-related brain potential study of musical expectancies. Music Perception 19: 487-528.

Huovinen, E. (2002). Pitch Class Constellations. Turku, Finland: Finnish Musicological Society.

Huron, D., \& Royal, M. (1996). What is melodic accent? Converging evidence from musical practice. Music Perception 13, 489-516.

Jones, M.R. (1987). Dynamic pattern structure in music: Recent theory and research. Perception \& Psychophysics 41, 621-634.

Judd, C. C. (1992). Modal types and $U t, R e, M i$ tonalities: Tonal coherence in sacred vocal polyphony from about 1500. Journal of the American Musicological Society 15, 428-457.

Judd, C. C., (Ed.) (1998). Tonal Structures in Early Music New York: Garland.

Kacarova-Kukudova, R. (1958). Propagation and variants of a Bulgarian folk dance, in Studia Belae Bartók Memoriae Sacra, 73-90.

Kohler, W. (1947). Gestalt Psychology. New York: Liveright.

Krenek, E. (1940). Music Here and Now (trans. Barthold Fles). New York: W.W. Norton.

Krumhansl, C., \& Shepard, R.N. (1979). Quantification of the hierarchy of tonal functions within a diatonic context. Journal of Experimental Psychology: Human Performance 5: 579-594.

Krumhansl, C., \& Keil, F.C. (1982). Acquisition of the hierarchy of tonal functions in music. Memory and Cognition 10: 243-251.

Krumhansl, C., Sandell, G., \& Sargent, D. (1987). The perception of tone hierarchies and mirror forms in twelve-tone serial music. Music Perception 5: 31-78.

Lecanuet, J.-P. (1996). Prenatal auditory experience. In: Deliège, I., and Sloboda, J., Eds. Musical Beginnings: Origins and Development of Musical Competence. New York: Oxford University Press, 3-34. 
Lecanuet, J.-P., C. Granier-Deferre, C., \& Bushnel, M.-C. (1995). Human fetal auditory perception. In: Lecanuet, J.-P., Fifer, W.P.,N.A. Krasnegor, \& Smotherman, W.P. (Eds.). Fetal Development: A Psychological Perspective. Hillsdale, N.J. Erlbaum Associates, 239-262.

Lecanuet, J.-P., Fifer, W.P., Krasnegor, N.A., \& Smotherman, W.P. (Eds.) (1995). Fetal Development: A Psychological Perspective. Hillsdale, N.J. Erlbaum Associates.

Lentz, D. (1961). Tones and Intervals of Hindu Classical Music. Lincoln: University of Nebraska Studies No. 24.

Lerdahl, F. (2001). Tonal Pitch Space. New York: Oxford University Press.

Levis, J.H (1964). Foundations of Chinese Musical Art. New York: Paragon Book Reprint.

Mathiesen, T.J. (1999). Apollo's Lyre. Lincoln: University of Nebraska Press.

Mawer, D. (1997). Darius Milhaud; Modality \& Structure in Music of the 1920s. Hants, England: Scolar Press.

Mithen, S. (1996). The Prehistory of the Mind. London: Thames and Hudson.

Nam, U. (1998). Pitch distributions in Korean court music: Evidence consistent with tonal hierarchies. Music Perception 16, 243-247.

Nketia, J.H.K. (1963). African Music of Ghana. Evanston, IL: Northwestern University Press.

Picken, L. (1959). Twelve ritual melodies of the Tang Dynasty. Studia Memoriae Belae Bartók, 145-171.

Rosch, E. (1978). Principles of categorization. In: Rosch, E., \& Lloyd, B.B. (Eds.), Cognition and Categorization. Hillsdale: Academic Press.

Rowell, L. (1992). Music and Musical Thought in Ancient India. Chicago: University of Chicago Press.

Sachs, C. (1943). The Rise of Music in the Ancient World. New York: W.W. Norton.

Schellenberg, E.G., and Trehub, S.E. (1996a). Children's' discrimination of melodic intervals. Developmental Psychology 32, 1039-1050.

Schellenberg, E.G., and Trehub, S.E. (1996b). Natural intervals in music: A perspective from infant listeners. Psychological Science 7, 272-277.

Schneider, M. (1957). Primitive music. In: Wellesz, E. (Ed.), The New Oxford History of Music. London: Oxford University Press, Vol. I.

Searle, J. (1992). The Rediscovery of Mind. Boston: MIT Press.

Studia Memoriae Bela Bartók Sacra (1957). London: Oxford University Press.

Terhardt, E. (1989). Characteristics of musical tones in relation to auditory acquisition of information. In: Proceedings of the First International Conference on Music Perception and Cognition. Kyoto, Japan: ICMPC Secretariat.

Thomson, W. (1993-94). The harmonic root: A fragile marriage of concept and practice. Music Perception $10,385-416$.

Thomson, W. (1998). On Miles and the modes. College Music Society Symposium 38, 16-32. 
Thomson, W. (1999). Tonality in Music: A General Theory. San Marino: Everett Books.

Trainor, L.J. (1997). The effect of frequency ratio on infants' and adults' discrimination of simultaneous intervals. Journal of Experimental Psychology: Human Perception and Performance 23, 1427-1438.

Trehub, S.E., Endman, M., \& Thorpe, A. (1990). Infants' perception of timbre: classification of complex tones by spectral structure. Journal of Experimental Child Psychology 49, 300-313.

Ushenko, A. (1953). Dynamics of Art. Bloomington, IN.: Indiana University Press.

Weddes, R. (1995). The Ragas of Early India. Oxford: Clarendon Press.

Wellesz, E. (Ed.), (1957). The New Oxford History of Music, I. London: Oxford University Press.

Werner, L.A., \& Marean, G.C. (1996). Human Auditory Development. Boulder, CO: Westview Press.

Wiora, W. (1959). Older than Pentatony. In: Studia Memoriae Belae Bartók Sacra, 183-206.

Zentner, M.R., \& Kagan, J. (1996). Perception of music by infants. Nature 383: 29-44. 